Western University

Scholarship@Western

Psychology

Psychology

1992

\title{
Measurement of beliefs about consciousness and reality
}

Imants Barušs

King's University College, baruss@uwo.ca

Robert J. Moore

Follow this and additional works at: https://ir.lib.uwo.ca/kingspsychologypub

Part of the Psychology Commons

Citation of this paper:

Barušs, Imants and Moore, Robert J., "Measurement of beliefs about consciousness and reality" (1992). Psychology. 5.

https://ir.lib.uwo.ca/kingspsychologypub/5 
Measurements of Beliefs 1

\section{Measurement of Beliefs about Consciousness and Reality ${ }^{1}$}

\author{
Imants Barušs \\ King's College \\ University of Western Ontario
}

\author{
Robert J. Moore \\ Campion College \\ University of Regina
}

(C) 1992 Imants Barušs and Robert J. Moore

Summary. -- The responses of 334 academics and professionals to a questionnaire concerning consciousness and beliefs about reality were used to develop 7 scales and to establish their reliability and norms.

The purpose of this paper is to describe the psychometric properties of seven scales that were developed from data collected as part of a study of the relationship between notions of consciousness and beliefs about reality. These scales can be used for measuring the extent to which a person endorses statements along the physical-transcendent dimension as well as determining, more specifically, their beliefs about consciousness and reality. The consciousness survey, which forms the basis of the scales, is outlined first. Second, a description of the scales is given along with their psychometric properties. Finally, the significance and utility of these scales is discussed.

\section{Consciousness Survey}

As part of the effort to resolve the confusion concerning the study of consciousness, Barušs and Moore developed and administered a questionnaire in an effort to find correlations between notions of consciousness and beliefs about reality. That work has been reported by Barušs and

\footnotetext{
${ }^{1}$ The authors thank the referees and editors of Psychological Reports for their helpful comments, and King's College for research grants which supported analyses of data and preparation of the manuscript. Correspondence should be addressed to Imants Baruss, King's College, 266 Epworth Avenue, London, Ontario, Canada N6A 2 M3.
} 
Moore (1989) and Barušs (1990) and, because it forms the basis of the scales for the measurement of beliefs about consciousness and reality, the work is summarized in this section.

Over 150 academic books and articles were read to obtain information about the understanding of consciousness in the sciences and philosophy. This information was used to develop a preliminary questionnaire of 158 items that was used for assessing the range of knowledgeability of educated people about consciousness. Analyses of 30 questionnaires, completed by university faculty from a variety of disciplines and graduate and undergraduate psychology students reduced the items to 32 for a pilot questionnaire.

Items for the measurement of beliefs about reality were also included in the pilot questionnaire. These items addressed epistemological, ontological, religious, and existential issues, as well as assessing values, purported extraordinary experiences, and intolerance of ambiguity. Seventy-two questionnaires were completed by university faculty and graduate students from a variety of disciplines, undergraduate psychology students, and mental health professionals. As a result of extensive data analyses, a number of minor changes were made to the instrument which was then employed in the survey stage of the research.

The survey questionnaire included 22 personally worded 4-point scales in Likert format and 67 impersonally worded 7-point scales also in Likert format concerned with consciousness and beliefs about reality, as well as other types of items and tasks. More than 1491 copies of the questionnaire were distributed to academics and professionals who could potentially write about consciousness in the academic literature. Of these, 1043 copies were mailed out as follows: 264 to a stratified sample of members of the Canadian Psychological Association, 171 to faculty across disciplines at the University of Saskatchewan, 143 to members of the Society for the History and Philosophy of Science, 132 to members of the Division of Theoretical Physics of the Canadian Association of Physicists, 100 to faculty and students at the California Institute of Integral Studies, 79 to members of the Canadian Psychiatric Association, 66 to authors of papers and books about consciousness, and 58 to persons associated with religious studies. The remaining, more than 448 copies, were distributed by electronic mail to readers of the electronically distributed Psychnet Newsletter. ${ }^{2}$

Three hundred and thirty-four completed questionnaires were returned. ${ }^{3}$ Sixty-nine percent $(\underline{\mathrm{n}}=229)$ of the responses were received from Canada, $27 \%(\underline{\mathrm{n}}=89)$ were from the United States, $1 \%(n=3)$ were from other countries, while the country of origin for the remaining $4 \%(n=13)^{4}$ could not be determined. The mean age was 44 years, with a standard deviation of 12 years; $27 \%$ $(\underline{n}=89)$ were women. Only $4 \%(\underline{n}=13)$ did not have a university degree, while $67 \%(\underline{n}=223)$ had obtained a doctorate. Forty-two percent $(\underline{\mathrm{n}}=140)$ were associated with psychology, $\overline{1} \overline{2} \%(\underline{\mathrm{n}}=40)$ with physics, $6 \%(\underline{n}=21)$ with philosophy; and fewer even were associated with disciplines such as computer science, psychiatry, and religious studies.

Responses to the 89 items concerning consciousness and beliefs about reality were extensively analyzed using SPSS-X Release 2.2 for IBM VM/CMS (SPSS Inc., 1983). From hierarchical cluster analysis emerged two large clusters; one contained items concerned with physicalism and conservative transcendence, while the other consisted of items related to extraordinary transcendent beliefs and the purported occurrence of unusual experiences. At each stage of agglomeration, the clusters were factor analyzed using the principal components method

\footnotetext{
${ }^{2}$ It is not possible to determine the exact number of copies distributed electronically. There were 448 recipients of a copy of the Psychnet Newsletter days before the questionnaire was automatically mailed out. However, as an electronic file, the questionnaire circulated in an uncontrolled manner. For example, one respondent found a copy in the AI Digest.

${ }^{3}$ Of these, $17 \%(\underline{\mathrm{n}}=55)$ had been sent out by electronic mail.

${ }^{4}$ Percentages do not add up to 100 because of rounding.
} 
of extraction with a varimax rotation. This process resulted in the identification of three factors for each cluster. ${ }^{5}$ These six factors have been described in detail by Barušs (1990, Chapter 5).

Upon examining the results of the analyses, it could be seen that items concerning consciousness and those concerning beliefs about reality more generally were found on the same factors. For example, the items, "Human consciousness is an emergent property of complex neural activity," and "There is no reality other than the physical universe" had factor loadings of .74 and .42 respectively on a factor entitled "Physicalism." In other words, specific ideas about consciousness and reality are elements of the same underlying beliefs. In this way, a judgement was made that a correspondence between notions of consciousness and beliefs about reality had been established.

Because of the intercorrelations of notions of consciousness and beliefs about reality, these six factors can be reconceptualized simply as dimensions of beliefs about consciousness and reality. Further, they could readily be used for the measurement of such beliefs. This paper is a description of the use of these six factors as scales for the measurement of beliefs about consciousness and reality.

\section{Description and Psychometric Properties of Scales}

The six factors extracted from the consciousness survey can be used as scales for the measurement of beliefs about consciousness and reality. To do this, the personally worded 4-point items in Likert format numbered with the prefix "B" by Barušs (1990, Chapter 5) are rescored -3.0, -1.5, 1.5, and 3.0. Similarly, the impersonally worded 7-point items numbered with the prefix "Q" are rescored $-3,-2,-1,0,1,2,3$, where " 0 " is the value assigned to "Don't know," blank and irregular responses. Each item is given unit weight. In addition, a seventh scale, called Transcendentalism, is made up of all the items of the other six scales appearing only once, with items from the Physicalism scale scored in reverse. This scale is a measure of the point at which a person's beliefs about consciousness and reality lie along a general physical-transcendental dimension. A brief description of these scales is given in Table $1^{6}$.

\footnotetext{
${ }^{5}$ Actually, four factors have been reported for the first cluster in Barušs (1990). The fourth factor to form in the first cluster is not considered here because it only consisted of two items.

${ }^{6}$ Further information about the instrument is available from the authors.
} 
Table 1

Description of Scales for Measurement of Beliefs About Consciousness and Reality

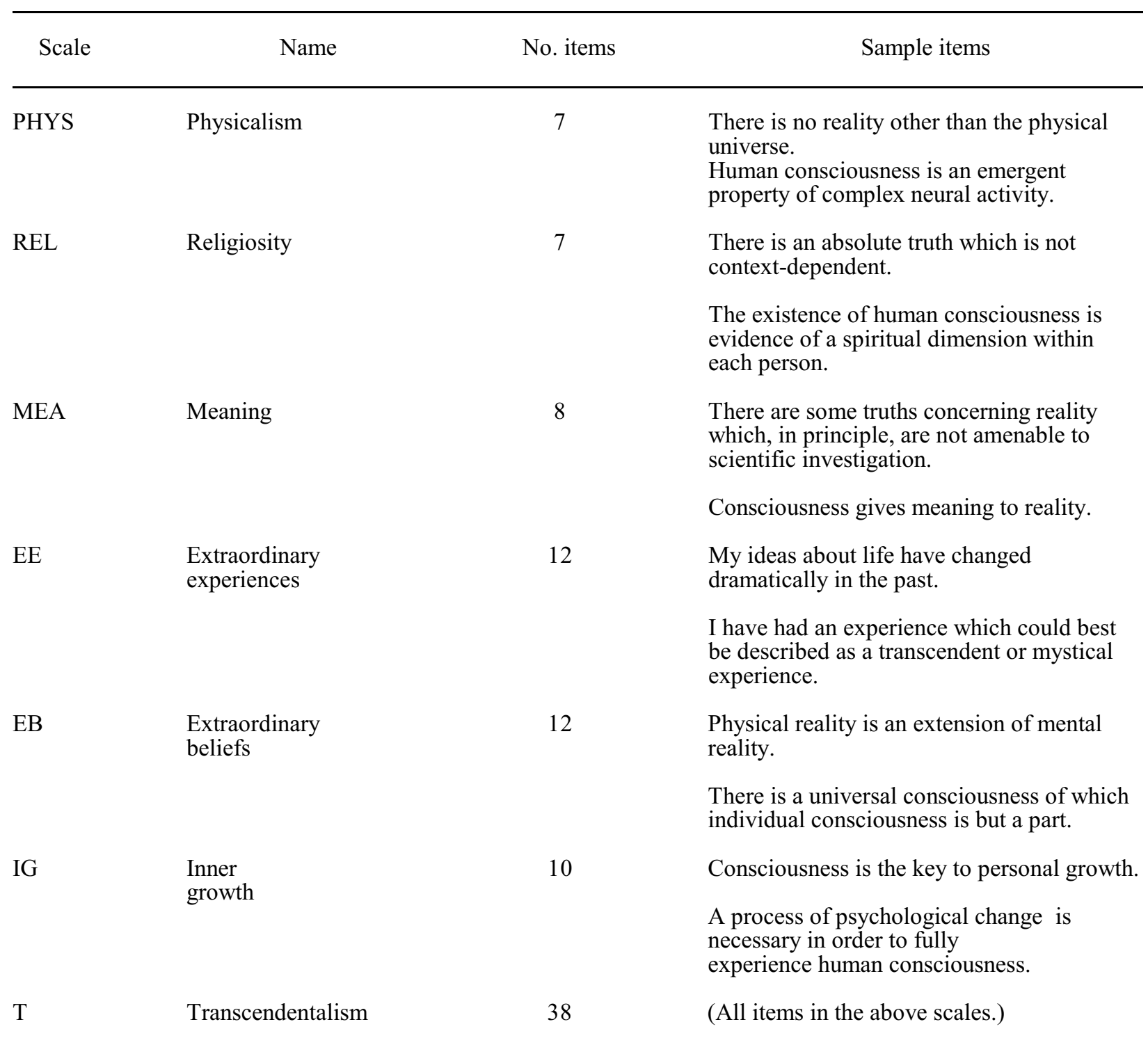

Norms and reliability for the scales were established by rescoring the responses of the 334 participants in the consciousness survey, obtaining totals for each of the scales and calculating values for means, standard deviations, average corrected item-total correlations, and Cronbach's alpha. In addition to computing the means and standard deviations for all respondents, these descriptive statistics were also estimated for women and men separately. The psychometric properties of the scales are given in Table 2. 
Measurements of Beliefs 5

Table 2

Psychometric Properties of Scales for Measurement of Beliefs About Consciousness and Reality

\begin{tabular}{|c|c|c|c|c|c|c|c|c|}
\hline \multirow[t]{2}{*}{ Scale } & \multicolumn{2}{|c|}{$\underline{\text { Women }}^{\mathrm{a}}$} & \multicolumn{2}{|c|}{ Men $^{\mathrm{b}}$} & \multicolumn{2}{|c|}{ All respondents ${ }^{\mathrm{c}}$} & \multirow[t]{2}{*}{$\underline{\mathrm{M}}_{\mathrm{r}}$} & \multirow[t]{2}{*}{$\underline{\alpha}$} \\
\hline & $\underline{M}$ & $\underline{\mathrm{SD}}$ & $\underline{M}$ & $\underline{\mathrm{SD}}$ & $\underline{\mathrm{M}}$ & $\underline{\mathrm{SD}}$ & & \\
\hline Physicalism & 1.3 & 8.3 & 4.4 & 9.1 & 3.5 & 9.0 & .57 & .82 \\
\hline Religiosity & .7 & 9.8 & -1.1 & 10.6 & -.6 & 10.4 & .62 & .85 \\
\hline Meaning & 6.4 & 9.9 & 2.6 & 11.2 & 3.6 & 11.0 & .57 & .84 \\
\hline $\begin{array}{l}\text { Extraordinary } \\
\text { experiences }\end{array}$ & 6.7 & 17.6 & -.3 & 16.4 & 1.6 & 17.0 & .61 & .89 \\
\hline $\begin{array}{l}\text { Extraordinary } \\
\text { beliefs }\end{array}$ & 4.2 & 14.8 & -4.5 & 14.6 & -2.2 & 15.1 & .60 & .89 \\
\hline $\begin{array}{l}\text { Inner } \\
\text { growth }\end{array}$ & 11.1 & 11.5 & 6.2 & 11.8 & 7.5 & 11.9 & .58 & .86 \\
\hline Transcendentalism & 14.8 & 43.8 & -3.9 & 42.3 & 1.2 & 43.4 & .56 & .95 \\
\hline
\end{tabular}

Note--Differences between mean scores for women and men were statistically significant for all scales except Religiosity at $\mathrm{p}<.01$ using Kruskal-Wallis $\underline{\mathrm{H}}$ tests. Nonparametric tests of significance were used because variances were not homogeneous. $\underline{M}_{r}=$ average corrected item-total correlation; $\underline{\alpha}=$ Cronbach's alpha.

${ }^{\mathrm{a}} \mathrm{n}=89$. ${ }^{\mathrm{b}} \underline{\mathrm{n}}=244$. ${ }^{\mathrm{c}} \underline{\mathrm{n}}=334$ (this includes one respondent whose sex could not be determine $\bar{d})$.

Consistent with the multifaceted approach advocated by Anastasi (1986), validity follows from the procedures used in the development of the scales as well as their psychometric properties. The process used in the development of the consciousness questionnaires and the analyses of the participants' responses as described in the section "consciousness survey" ensures that the content of items faithfully represents statements in the academic literature and that the six scales are assessing separable constructs. Good values of average corrected item-total correlations and Cronbach's alpha for all seven scales are indicative of the relative homogeneity of constructs measured by the scales. At this point in their development and utilization, these scales demonstrate good reliability and validity.

\section{Discussion}

It has been observed frequently that, within the western intellectual tradition, belief systems vary along a physical-transcendental dimension (e.g., Frank, 1977; Harman, 1987; Osborne, 1981). Coan (1968), Krasner and Houts (1984), and Kimble (1984) have empirically examined the 
presuppositions of psychologists and found underlying dimensions which are compatible with a physical-transcendental dimension. The existence of the seven scales, with good reliability and validity, identified in this study lends empirical support to and further clarifies such underlying dimensions within a more general educated public.

The Transcendentalism scale can be used for measuring the point along the physicaltranscendental dimension of a person's beliefs about consciousness and reality. Furthermore, a profile can be obtained for each person by examining their scores on the six original scales. This allows a detailed assessment of a person's beliefs about consciousness and reality. Because a large number of items concerning transcendental beliefs were developed, these scales may prove particularly useful in making discriminations towards the transcendent end of the physicaltranscendental dimension. For these reasons, these scales might be useful in measurement of beliefs about consciousness and reality.

\section{References}

Anastasi, A. (1986) Evolving concepts of test validation. Annual Review of Psychology, 37, 1-15. Barušs, I. (1990) The personal nature of notions of consciousness. Lanham, MD: University Press of America.

Barušs, I. \& Moore, R. J. (1989) Notions of consciousness and reality. In J. E. Shorr, P. Robin, J. Connella, \& M. Wolpin (Eds.), Imagery: current perspectives (pp. 87-92). New York: Plenum.

Coan, R. W. (1968) Dimensions of psychological theory. American Psychologist, 23, 715-722.

Frank, J. D. (1977) Nature and functions of belief systems: humanism and transcendental religion. American Psychologist, 32, 555-559.

Harman, W. W. (1987) Survival of consciousness after death: a perennial issue revisited. In J. S. Spong (Ed.), Consciousness and survival: an interdisciplinary inquiry into the possibility of life beyond biological death. Sausalito, CA: Institute of Noetic Sciences.

Kimble, G. A. (1984) Psychology's two cultures. American Psychologist, 39, 833-839.

Krasner, L., \& Houts, A. C. (1984) A study of the "value" systems of behavioral scientists. American Psychologist, 39, 840-850.

Osborne, J. (1981) Approaches to consciousness in North American academic psychology. Journal of Mind and Behavior, 2, 271-291.

SPSS Inc. (1983) SPSS $^{\mathrm{x}}$ user's guide [Computer program manual]. New York: McGraw-Hill. 